\title{
Design of Sierpinski Gasket Fractal Antenna using Proximity coupled feed mechanism for Multiband Applications
}

\author{
Ashish Dhankhar ${ }^{1}$, Jaswinder Kaur ${ }^{2}$ \\ Student, Department of Electronics and Communication Engineering, Thapar University, Patiala, Punjab, India ${ }^{1}$ \\ Lecturer, Department of Electronics and Communication Engineering, Thapar University, Patiala, Punjab, India ${ }^{2}$
}

\begin{abstract}
In this paper, the design of Sierpinski Gasket fractal antenna using proximity coupled feed for multiband applications is presented. Certain properties of designed antenna structure like return loss and directivity are analyzed and simulated using 3D electromagnetic simulator CST MWS 14.0. The proposed antenna is designed on FR-4 lossy substrate with thickness $1.6 \mathrm{~mm}$ and relativity permittivity 4.4 . The proposed antenna has resulted after the successful combination of first, second and third iterations. Simulated results show that from second iteration onwards, the antenna starts showing multiband behaviour at different frequency bands. The broadband and multiple frequency features of fractal antenna are presented and discussed.
\end{abstract}

Keywords: Sierpinski Gasket, Proximity coupled Feed, CST MWS V14.0, Return Loss, Directivity, Fractal antenna and Multiband.

\section{INTRODUCTION}

Though the nature of wireless communication and its applicability is very abstruse and complex during the past few decades, even then the necessity for wireless communication is beyond the maximum peak. Nowadays, wireless technology requires antenna with wider bandwidth and smaller dimensions, an antenna that covers multiple applications using a single device and therefore efforts are being made to concentrate more on the fractal antenna structures [1]. The word fractal comes from Latin 'fractus' which means broken lines. Fractal geometry is formed using iterative process that leads to self-similarity and self-affinity structure [2]. The Sierpinski Gasket was introduced by Waclaw Sierpinski in 1915 and it is an important part of fractal set. Fractal antenna is used for multiband applications because it is small in size, low cost and easy to fabricate [3]. Fractal concept has been applied to many branches of science and engineering including fractal electrodynamics for radiation and propagation [4]. There are various type of fractal antenna geometries discussed in literature available [5]:

- $\quad$ The Von Koch curve

- The Sierpinski (Gasket and Carpet)

- Minkowski fractal island

Most of the fractal geometry antennas have two common properties which are multi-banding and space-filling [6]. Proximity Coupled feeding technique has been used in this paper because it provides maximum bandwidth and also reduces the spurious radiation and mutual coupling [7].

Because of the remarkable properties that fractal possesses, it is becoming an attractive way in designing antenna. The disadvantages of fractal are gain loss, numerical limitation and computational complexity involved[8]. Fractal structure is used to represent structure in nature such as cloud, mountain, flower and star [9]. In this paper, design of Sierpinski Gasket fractal antenna starts with an equilateral triangle with operational frequency $1 \mathrm{GHz}$ to $4 \mathrm{GHz}$. Figure 1 shows the zero/initial, first and second iteration of proposed Sierpinski Gasket antenna. Further, the details of proposed antenna design are illustrated and discussed in this paper.

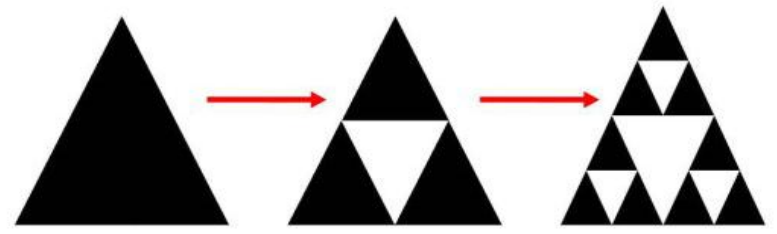

Figure 1: Sierpinski Triangle for Zero, First and Second Iteration [6]

II. ANTENNA DESIGN AND SPECIFICATIONS

The procedure of how to make Sierpinski Gasket fractal antenna is shown in Figure 2(a), Figure 2(b) and Figure 2(c). The numerical design values of various antenna parameters are presented in Table I.

TABLE I: PHYSICAL DIMENSIONS OF PROPOSED ANTENNA

\begin{tabular}{|l|l|l|}
\hline S.NO & Antenna Parameter & Design Value \\
\hline 1 & Dielectrical Material & FR4_LOSSY \\
\hline 2 & Substrate Height & $1.6 \mathrm{~mm}$ \\
\hline 3 & Flare Angle & 60 \\
\hline 4 & Side Length & $46.80 \mathrm{~mm}$ \\
\hline 5 & Height & $40.50 \mathrm{~mm}$ \\
\hline 6 & Scale Factor & 2 \\
\hline 7 & Dielectric Constant & 4.4 \\
\hline
\end{tabular}


The final designed Sierpinski Gasket antenna shown in Figure 2(c) is designed on FR-4 Lossy Substrate (dielectric constant 4.4) with substrate thickness of 1.6 $\mathrm{mm}$. There are three important parameters for the designing of designed antenna: height of substrate, dielectric material of substrate and resonant frequency. First a simple equilateral triangle is taken as shown in Figure 2(a). For first iteration, remove central inverted triangle from main triangle and process is repeated for further iteration [9]. This antenna is fed through proximity coupled feeding technique which provides maximum bandwidth with the benefit of minimizing spurious radiations.

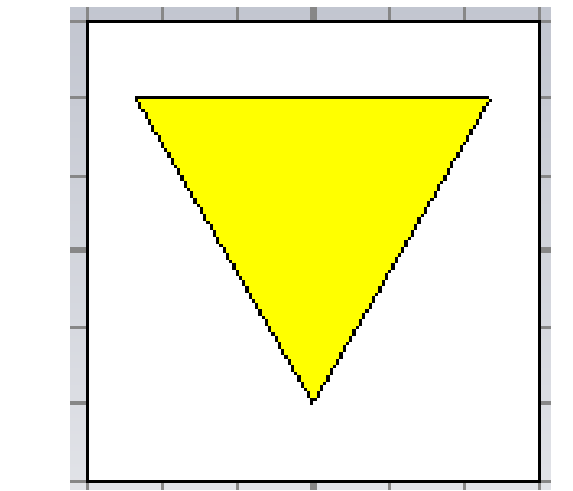

Figure 2(a): Zero (Initial) iteration of designed antenna

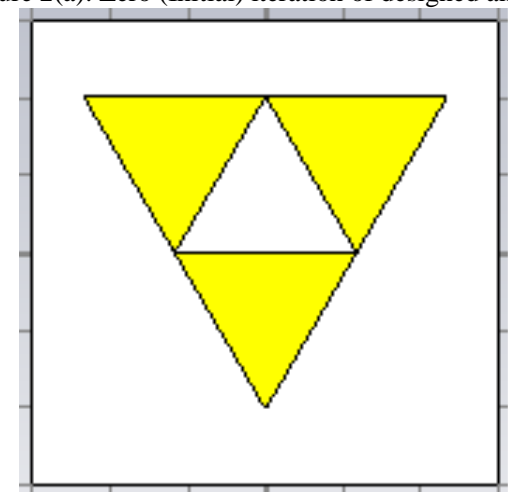

Figure 2(b): First iteration of designed antenna



III.RESULTS AND DISCUSSION

The dimensions of designed antenna are optimized by hit and trial method using parameter sweep option available in transient solver window of CST MICROWAVE STUDIO Version 14.0. $\mathrm{S}_{11}$ parameter indicates Return
Loss and it is defined as maximum reflection of power from the given antenna. The designed antenna structure is simulated starting from the initial iteration/generator to second iteration. The corresponding return loss curves are also shown side by side for all the three iterations thus illustrating the value of frequency of resonance and return loss. As the number of iterations increase, numbers of resonating frequencies also increase.

The second iteration of the proposed antenna shows multiband behavior. Directivity is defined as maximum value of directive gain [1]. The simulated return loss curves of proposed antenna for initial, first and second iterations are shown in Figures 3(a), 4(a) and 5(a) respectively. $3 \mathrm{D}$ radiation patterns that represent directive gain are also analyzed for all the three iterations using the field monitors option in CST MWS V14.0 and are presented in Figures 3(b), 4(b), 4(c), 5(b), 5(c) and 5(d) correspondingly. The quick analysis of return loss and directivity for all the three resonating frequencies is tabulated in Table II.

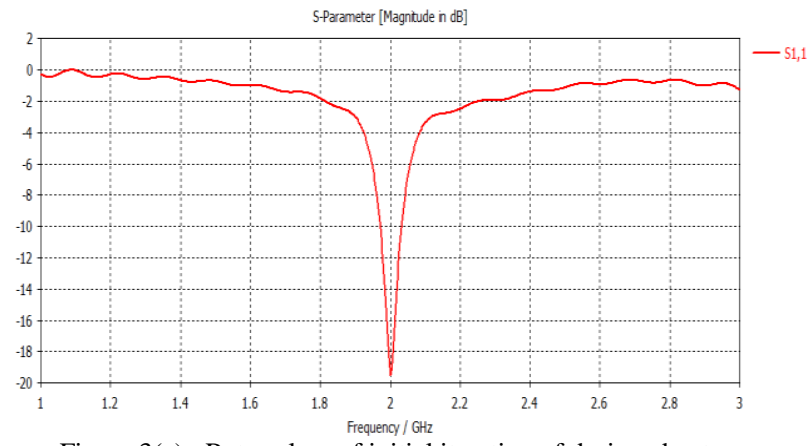

Figure 3(a): Return loss of initial iteration of designed antenna

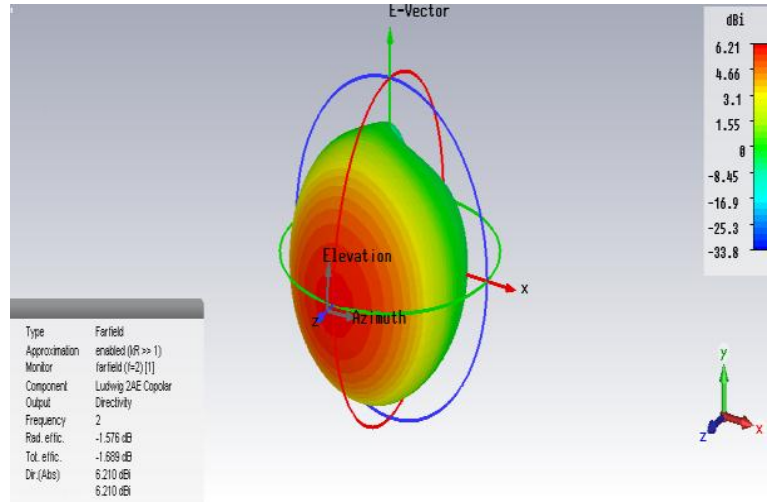

Figure 3(b): Directivity of initial iteration of designed antenna at $2 \mathrm{GHz}$

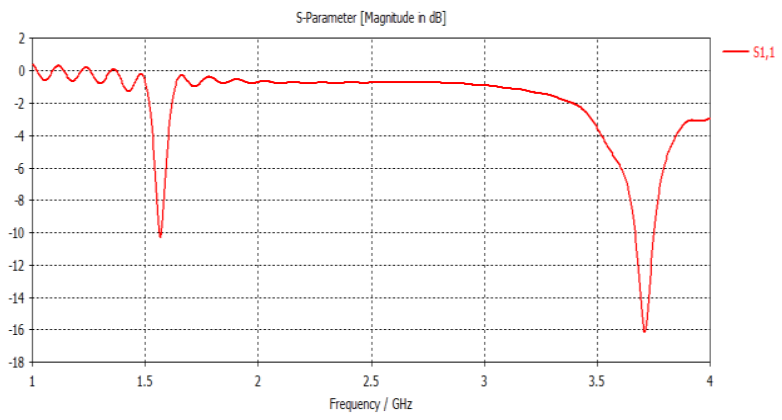

Figure 4(a): Return loss of first iteration of designed antenna 


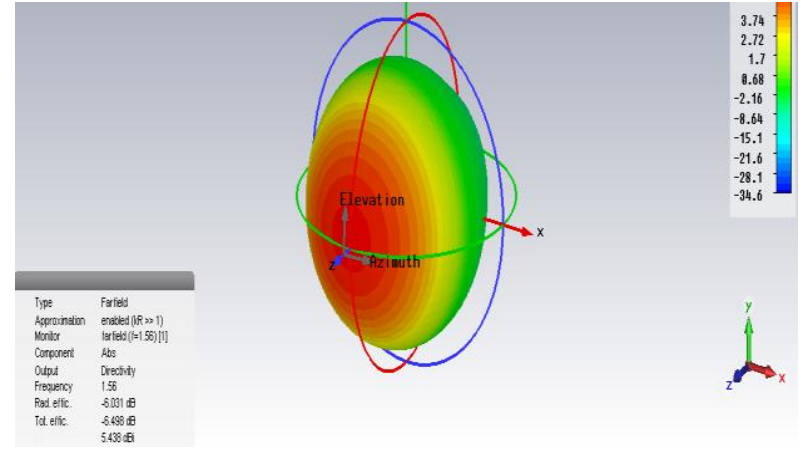

Figure 4(b): Directivity of first iteration of designed antenna at $1.56 \mathrm{GHz}$



Figure 4(c): Directivity of first iteration of designed antenna at $3.71 \mathrm{GHz}$

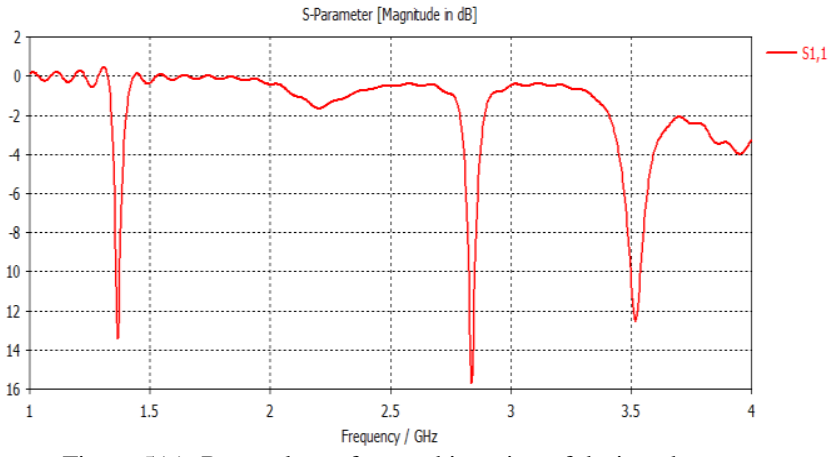

Figure 5(a): Return loss of second iteration of designed antenna

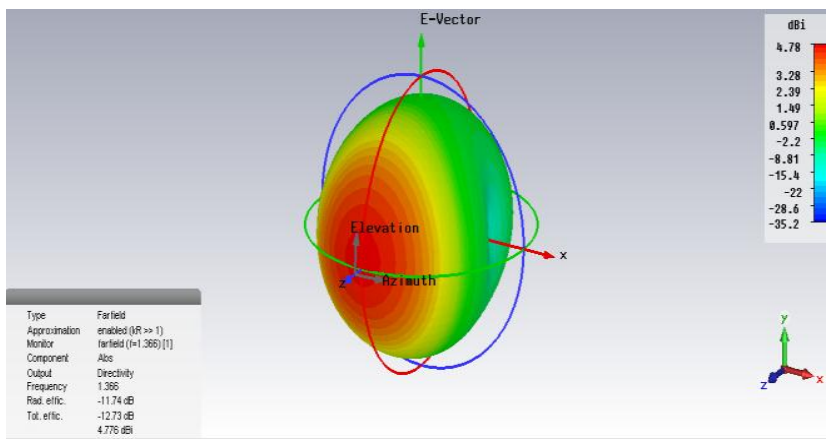

Figure 5(b): Directivity of second iteration of designed antenna at $1.36 \mathrm{GHz}$

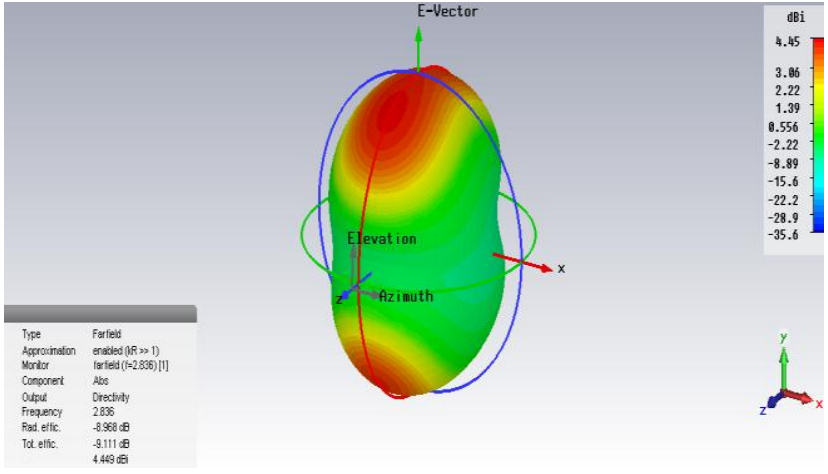

Figure 5(c): Directivity of second iteration of designed antenna at $2.83 \mathrm{GHz}$

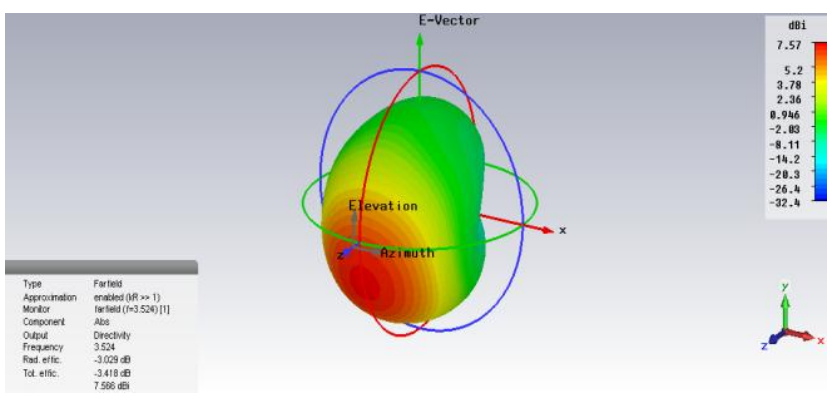

Figure 5(d): Directivity of second iteration of designed antenna at $3.52 \mathrm{GHz}$

TABLE II: COMPARISON OF RETURN LOSS AND DIRECTIVITY AT VARIOUS FREQUENCIES FOR ZERO, FIRST AND SECOND ITERATION

\begin{tabular}{|l|l|l|l|}
\hline $\begin{array}{c}\text { ITERATIO } \\
\mathrm{N}\end{array}$ & $\begin{array}{c}\text { RETUR } \\
\mathrm{N} \\
\text { LOSS }\end{array}$ & $\begin{array}{c}\text { DIRECTIVIT } \\
\mathrm{Y} \\
(\mathrm{dBi})\end{array}$ & $\begin{array}{c}\text { FREQUEN } \\
\text { CY } \\
(\mathrm{GHz})\end{array}$ \\
\hline First & -19.5 & 6.21 & 2 \\
\hline Second & -10.3 & 3.70 & 1.66 \\
\hline Second & -16.1 & 7.34 & 3.71 \\
\hline Third & -13.4 & 4.77 & 1.36 \\
\hline Third & -15.8 & 4.44 & 2.83 \\
\hline Third & -12.5 & 7.56 & 3.52 \\
\hline
\end{tabular}

The initial iteration starts with a triangular patch resonating at the frequency of $2 \mathrm{GHz}$ with return loss -19.5 $\mathrm{dB}$ and directivity $6.21 \mathrm{dBi}$. After this iteration, Sierpinski Gasket antenna resonates at two different frequencies viz. $1.66 \mathrm{GHz}$ and $3.71 \mathrm{GHz}$ with return loss values $-10.3 \mathrm{~dB}$ and $-16.1 \mathrm{~dB}$ and directivity $3.70 \mathrm{dBi}$ and $7.34 \mathrm{dBi}$ respectively. In the last iteration Sierpinski Gasket fractal antenna resonates at three different frequencies viz. 1.36 $\mathrm{GHz}, 2.83 \mathrm{GHz}$ and $3.52 \mathrm{GHz}$ with return loss values $13.4 \mathrm{~dB},-15.8 \mathrm{~dB},-12.5 \mathrm{~dB}$ having directivity $4.77 \mathrm{dBi}$, $4.44 \mathrm{dBi}$, and $7.56 \mathrm{dBi}$ respectively.

\section{IV.CONCLUSION}

Sierpinski Gasket fractal antenna with proximity feeding technique has been presented in this paper. This fractal antenna has been analysed using CST Microwave Studio V14.0. It is observed that from second iteration onwards, it starts exhibiting multiband behaviour with an acceptable frequency response at multiple frequencies simultaneously. 
As number of iterations increase, number of resonant frequencies also increases which gives multiband performance to the Sierpinski Gasket antenna structure. The results shows that antenna gives appreciable return loss and directivity with miniaturization and is best suited for wireless applications.

\section{ACKNOWLEDGMENT}

The authors greatly acknowledge the help provided by Electronics and Communication Engineering Department, T.U., Patiala by providing the necessary software for designing antenna, testing equipment's and various infrastructural facilities for the successful completion of this paper.

\section{REFERENCES}

[1] C. Balanis, "Antenna Theory: Analysis and Design" 2nd edition, New York, Wiley, 1997.

[2] Mandelbort, B.B. Petigen, "The Fractal geometry of Nature" W. H. Freeman and Company, 1982.

[3] R. Garg, P. Bharti and A. Ittipiboon, "Microstrip antenna design handbook" Artech House, Norwood, MA, 2001.

[4] D.L. Jaggard, "On fractal electrodynamics" in recent advances in electromagnetic theory, H.N. Kritikos and D.L. Jaggard, edition, New York: Springer- Verlag, pp. 183-224, 1990.

[5] L. Lizzi and G. Oliveri, "Hybrid design of a fractal shaped GSM/UMTS Antenna" Microwave and optical technology Letters, vol. 50, no.3, pp. 825-829, 2010.

[6] G.F. Tsachtsiris, C.F. Soras, M.P. Karaboikis and V.T. Makois, "Analysis of Modified Sierpinski Gasket Monopole antenna Printed on Dual Band Wireless Devices" IEEE Transactions on Antennas and Propagation, vol. 52, no. 10, pp. 2571-2579, 2004.

[7] Carlos Puente Blairada, Jordi Romeu, Rafel Pous and Angle Cardama, "On the behavior of the Sierpinski Multiband Fractal Antenna", IEEE Transactions on Antennas and Propagation, vol.46, no.4, pp. 517-524, 1998.

[8] W.L. Chen and G.M. Wang, "Small size edge-fed Sierpinski Carpet microstrip patch antenna" PIERS C, vol.3, pp. 195-202, 2008.

[9] Philip Felber, "Fractal Antennas", Illinois institute of Technology, 2nd edition, 2001 